\title{
Optimization of Production Process of Nano-Calcium Oxide from Pinctada maxima Shell by Using Taguchi Method
}

\author{
Kendri Wahyuningsih ${ }^{1,2, *}$, Jumeri ${ }^{2}$, and Wagiman ${ }^{2}$ \\ ${ }^{1}$ Indonesian Center for Agricultural Postharvest Research and Development, \\ Jl. Tentara Pelajar No. 12 Cimanggu-Bogor 16114, Jawa Barat, Indonesia \\ ${ }^{2}$ Department of Agroindustrial Technology, Universitas Gadjah Mada, \\ Jl. Flora No. 1, Bulaksumur, Caturtunggal, Depok, Sleman, Yogyakarta 55281, Indonesia
}

${ }^{*}$ Corresponding author:

email: kendriwahyuni@gmail.com

Received: March 13, 2018

Accepted: August 16, 2018

DOI: $10.22146 /$ ijc.33871

\begin{abstract}
West Nusa Tenggara is a center of sea oyster farming for Pinctada maxima in Indonesia. The calcium carbonate $\left(\mathrm{CaCO}_{3}\right)$ compounds in the shell are one of the decomposed natural minerals to produce calcium oxide ( $\mathrm{CaO}$ ) compound which can be used as an alternative heterogeneous catalyst in nanometer scale. This research aims to discover the control factors which influence the production process of nanometer-scaled $\mathrm{CaO}$ heterogeneous catalyst and choose the best condition in its production process with a better-quality product. Calcined pearl shell (P. maxima) powder was milled by using Shaker mill. The experimental design was performed by using Taguchi method with an orthogonal matrix consisting of 4 control factor variables, i.e., milling time, ball-topowder weight ratio, the diameter of milling beads and extent of milling the vial. The selection of best control factor variable combination was computed by using a multiresponse loss function. ANOVA analysis shows that the product quality parameter of nano-calcium oxide was influenced by all experiment factors. Multi-response loss function analysis resulted an optimum factor and level combination under process condition happens during the duration of $3 \mathrm{~h}$ milling, the ball-to-powder weight ratio is 1:10, the diameter of milling beads is $5 \mathrm{~mm}$ and 55\% extent of filling the vial.
\end{abstract}

Keywords: Pinctada maxima; heterogeneous catalyst; Taguchi method; multi-response loss function

\section{- INTRODUCTION}

The catalyst is one of the materials needed in the industries of chemistry, pharmacy, energy or any other industries to accelerate the reaction so that the production cost and time can be lowered. A homogeneous catalyst is the preferred by producers because it has high performance and catalytic activity in accelerating reaction to produce the product [1]. However, homogeneous catalyst separation process of the product needs an advanced treatment which has an impact on the rise of cost and production time [2], toxic, flammable, and corrosive [3-5].

The use of a heterogeneous catalyst to minimize production cost because it is easier in the separation and purification process from the produced products $[3,6]$.
However, the catalyst has corrosive properties, expensive and not environmentally friendly so it is necessary to find another alternative that is a green catalyst. Green catalyst development by using natural material such as biomass is easily renewable, sustainable, affordable, simple process, cleaner production, nontoxic, non-corrosive, and environmentally friendly [3,78] as well as reusable [9]. Department of marine and fisheries reported that West Nusa Tenggara province (Indonesia) is the pearl oyster cultivation center of Pinctada maxima and its production reaches 13.02 ton/year. The shell wastes of this Mollusca group are rich in calcite which can produce calcium oxide compounds. Similarly, on an oyster shell, the average of calcite is around 95\% [10-11], on Achatina fulica shell is 88-99\% 
[12]. Calcium oxide from Mollusca shell as a heterogeneous catalyst has several advantages, i.e., high alkalinity level, inexpensive raw material and renewable [6,12]. Nurhayati et al. also reported that calcium oxide catalyst from the shell of blood clam (Anadara granosa) has an advantage as it is non-toxic and the soap forming byproduct of transesterification reaction is lessened than the homogeneous catalyst [13]. However, this heterogeneous catalyst has low catalytic performance and activity [14].

Nanotechnology approach by minimizing the catalyst particle size can improve the performance of the catalyst [15]. It is because the surface area of the particle becomes larger, so the collision process or mobilization between reactant particles transpire more active and faster [16]. However, to assign the nano-catalyst making process with the top-down method is not easy to generate a stable product because it is influenced by various control factors as well as noise factors. Thus, it needs a proper experimental design to produce a good quality product performance. Experiment design using Taguchi method is possible to perform an experiment which involves a lot of factors and levels in short period, cost-effective and reduces the raw material or chemical material used without overriding the influential factors [17-18]. It is because analysis in Taguchi uses orthogonal array (OA) and signal to noise ratio (SNR) equipment. Besides, Taguchi analysis uses ANOVA which can detect differences in performance average from the tested parts group.

This research aims to identify the control factors which take effect on particle size and specific surface area of nano-calcium oxide product from P. maxima shell as well as to determine a robust nano-calcium oxide making process combination against outside interference (noise). Process condition which generates the best result is expected to be able to be used as the reference source or information in nanoparticle production using ball mill technique.

\section{- EXPERIMENTAL SECTION}

\section{Materials}

Pearl oyster shell of P. maxima from Autore PT. (West Nusa Tenggara-Indonesia), ethanol 96\% (technical grade), distilled water.

\section{Instrumentation}

The main equipment used in this research are Shaker Mill PPF-UG, furnace, oven mermert, disk mill, sieve size 200 mesh. The instruments used are X-Ray Diffraction Rigaku Miniflex600, X-Ray Fluorescence Rigaku, Scanning Electron Microscope-Energy Dispersive X-Ray SU 3500 Hitachi, Transmission Electron Microscopy JEOL/EO JEM-1400, Fourier Transform Infra Red Spektrofotometer Nikolet iS10 and Brunauer Emmett Teller Quantachrome NovaWin Instruments version 11.03 .

\section{Procedure}

\section{Pearl oyster shell milling}

Pearl oyster shells type P. maxima are cleaned and washed using warm water, sanded and then heated in an oven at $110^{\circ} \mathrm{C}$ for an hour. After cooling down, the shells are milled using disk mill until these turn into powder. Then, the powder is strained by using the sieve 200 mesh. The pearl oyster shell powder is calcined with the furnace at temperature $650^{\circ} \mathrm{C}$ for $24 \mathrm{~h}$ to obtain calcium oxide $(\mathrm{CaO})$ compounds. The purpose of this calcination is to transform calcium carbonate into more reactive calcium oxide as a heterogeneous base catalyst.

\section{The selection of nano-Calcium oxide production method}

Nano-Calcium oxide production aims to produce a green catalyst which is inexpensive, high catalytic activity and environmentally friendly. A top-down method using high energy ball mill process has been selected to produce nano-Calcium oxide product using Shaker Mill UPP-FG.

\section{Experimental design}

Design of experiment for nano-calcium oxide production from pearl oyster ( $P$. maxima) shell uses the Taguchi method. The first steps of Taguchi method are identification and selection of the independent factors, based on the prior researches, literature, information from equipment technicians and machineability condition, four factors are chosen, i.e. milling time, ballto-powder weight ratio, the extent of filling the vial, and the diameter of milling beads. 
Table 1. Taguchi controllable factors and their levels

\begin{tabular}{cclccc}
\hline \multirow{2}{*}{ Num. } & & \multicolumn{2}{c}{ Factor } & \multicolumn{3}{c}{ Setting Levels } \\
\cline { 3 - 6 } & & & 1 & 2 & 3 \\
\hline 1. & A & Milling time (h) & 1 & 2 & 3 \\
2 & B & Ball-to-powder weight ratio & $1: 10$ & $2: 10$ & $3: 10$ \\
3. & C & Extent of filling the vial (\%) & 45 & 50 & 55 \\
4. & D & Diameter of milling beads (mm) & 5 & 10 & 20 \\
\hline
\end{tabular}

The second step, determine the factor of levels and the selection of orthogonal array matrix. The level value from each factor in nano-calcium oxide production process is determined based on the range limit and extreme value from the result of previous research, references as well as the capacity of machineability technology that is used. The material type of milling medium is carbon steel, and milling beads are Alumina with different diameter factor of levels variation. The factor of levels for milling time is 1,2 , and $3 \mathrm{~h} \mathrm{[19-20].}$ Level for ball-to-powder weight ratio is $1: 10 ; 2: 10$; and $3: 10[7,20]$. Meanwhile, the chosen extent of filling the vial is level 45, 50, and $55 \%$ [19]. Based on the tabulation result in Table 2, the suitable orthogonal array matrix obtained is $\mathrm{L}_{9}\left(3^{4}\right)$ with such design as in Table 2 and 3.

The third step, experiment for nano-calcium oxide production. The product making the process from the pearl oyster (P. maxima) shell is according to Mosaddegh et al. method which has been combined its production process parameter according to Table 3 [21].

Fourth step, performing the product quality parameter testing. The obtained products are tested for its quality which includes the particles size and specific surface area supported by using SEM and TEM instruments.

Fifth step, analysis of data. The data is processed through the processing of mean data, $\mathrm{S} / \mathrm{N}$ ratio, analysis of variance (ANOVA), loss function multi-response. The characteristics of nano-calcium oxide are determined and identified based on the quality type from the suitable $\mathrm{S} / \mathrm{N}$ ratio. The characteristic of particle size with $\mathrm{S} / \mathrm{N}$ ratio type of smaller is the better and specific surface area with $\mathrm{S} / \mathrm{N}$ ratio type of large is the better in sequence according to equation (1) and (2). ANOVA is used to find out the factors contributing which influence the experiment result (setting level). The calculation of loss function multi-response to determine the optimal treatment combination is based on all tested quality characteristics.

$$
\begin{aligned}
& \eta=-10 \log \left(\frac{1}{\mathrm{n}} \sum_{\mathrm{r}=1}^{\mathrm{r}} \mathrm{yi}^{2}\right) \\
& \eta=-10 \log \left(\frac{1}{\mathrm{n}} \sum_{\mathrm{r}=1}^{\mathrm{r}} \frac{1}{\mathrm{yi}^{2}}\right)
\end{aligned}
$$

where $\eta$ is the $S / N$ ratio value, $n$ is the number of repetition in each experiment, and $\mathrm{y}_{\mathrm{i}}$ is the value in each i-th repeated experiment.

Sixth step, application of the multi-response signal to noise. The calculation to perform the making of optimal factor levels recommendation on nano-calcium oxide production uses a multi-response calculation based on the approach of the Taguchi loss function method by using equation (3). Subsequently, the result is transformed into a signal to noise ratio (SNR) by using equation (4) and created a factor effect table so that the best optimal factor levels condition are obtained.

$$
\begin{aligned}
& \mathrm{TL}_{\mathrm{j}}=\sum_{\mathrm{i}=1}^{\mathrm{r}} \mathrm{W}_{\mathrm{i}} \mathrm{xN}_{\mathrm{ij}} \\
& \eta_{\mathrm{j}}=-10 \log \left(\mathrm{TL}_{\mathrm{j}}\right)
\end{aligned}
$$

where $\mathrm{TL}_{\mathrm{j}}$ is the total loss function, $\mathrm{W}_{\mathrm{i}}$ is the number of response variable, and $\eta_{j}$ is SNR value [28-29].

Seventh step, confirmation experiment. Confirmation experiment is the last process of experiment design process which aims to validate the conclusion gained during the analysis stages [20] and to test the combination of factor and level. The result of the confirmation experiment must be within the optimum confidence interval. The confidence interval for confirmation experiment is calculated based on equation (5).

$$
\mathrm{Cl}_{\text {mean }}= \pm \sqrt{\mathrm{F}_{\alpha ; \mathrm{V} 1: \mathrm{v} 2} \times \mathrm{MS}_{\mathrm{e}} \mathrm{x}\left|\frac{1}{\mathrm{n}_{\mathrm{eff}}}+\frac{1}{\mathrm{r}}\right|}
$$


where, $F_{\alpha ; 11: v 2}$ is F-ratio value from table, $\alpha$ is confidence level, $\mathrm{v}_{1}$ is degree of freedom for the numerator corresponding to a mean and always equal to 1 for a confidence interval, $\mathrm{v}_{2}$ is the degree of freedom for denominator corresponding to the degree of freedom from pooled error variation, $\mathrm{MS}_{\mathrm{e}}$ is pooled error variation, $n_{\text {eff }}$ is the amount of effective observation and $r$ is the number of replication.

\section{Characterization of Nanoparticle CaO}

The chemical compounds of the sample powder obtained from the milling by using Shaker Mill UPP-FG are analyzed by using X-Ray Fluorescence Rigaku Nex $\mathrm{QC}^{+}$quantEZ. A total of $3 \mathrm{~g}$ of samples is pressed into a molded container evenly and compact. Then, it is put into the XRF tools and the measurement analysis can be begun. FTIR spectrophotometer to analyze the functional group of sample composer uses Nicolet iS10 ThermoScientific instrument. FT-IR measurement is performed at a wavelength of 500 to $4000 \mathrm{~cm}^{-1}$ [24]. XRay Diffraction Rigaku Miniflex600 operated by with $\mathrm{Cu}$ Ka monochromatic rays, the wavelength is $\lambda=1.54060 \AA$. The $2 \theta$ angle range is started from $2^{\circ}$ up to $80^{\circ}$ with scanning interval $0.02^{\circ}$ every $10 \mathrm{~min}$ on room temperature. The determination of nanoparticle crystal size means uses the approach from Deybe-Scherrer equation $[9,25]$.

Nanoparticle specific surface area is analyzed by using the Brunauer Emmett Teller/BET method. A total $0.1-1.0 \mathrm{~g}$ of a sample is made in a pellet form and it is operated on tools with heating mantle temperature condition and the velocity of $\mathrm{N}_{2}$ bubbles is 3-5 bubbles/sec. Scanning Electron Microscope SU 3500 Hitachi is for finding out the nanoparticle morphology, and Energy Dispersive X-Ray is used to analyze the chemical composition of sample composer. The instrument is operated on electron shooting acceleration voltage of $5.00 \mathrm{kV}$ and $5.1 \mathrm{~mm}$ WD. Meanwhile, Energy Dispersive $\mathrm{X}$-Ray is operated on electron shooting acceleration voltage of $15.00 \mathrm{kV}$ for $30 \mathrm{sec}$ with the resolution level of $131.6 \mathrm{eV}$. Sample analysis using New JEOL TEM (JEM 1400 ) is performed to see the structure and the shape of nanoparticle pores by using a higher resolution. The operation condition is carried out at a $120 \mathrm{kV}$ acceleration voltage.

\section{- RESULTS AND DISCUSSION}

Indonesia is an archipelago country with many gulfs among the islands. One of the islands in West Nusa Tenggara province whose gulfs are protected from wind and waves. The water condition of these gulfs has been developed as the center of pearl oyster cultivation with the rate of pearl production reaching 13.02 ton per year based on Department of Marine and Fisheries-West Nusa Tenggara report. This production has produced wastes of the shell with the biggest amount of it coming from P. maxima type. In order to boost the economic value of these wastes, $P$. maxima shell can be used as the raw material of catalyst industries. The analysis result which employed XRF method demonstrates that $P$. maxima shells have a high calcium oxide of $93.53 \%$. It is also supported by the data which appears on the analysis employing SEM-EDS instruments (Fig. 1) and FTIR analysis (Fig. 2). The data displayed in Fig. 1 demonstrates that the calcium oxide on $P$. maxima shell is $95.45 \%$ with its content of chemical elements are $\mathrm{Ca}$, $\mathrm{O}, \mathrm{Cu}$ and $\mathrm{Al}$. The peak of Ca spectra appears on 3.690 $\mathrm{keV}$ energy band with the highest percentage is $68.22 \%$, while other elements in the sequence are O $28.28 \%, \mathrm{Cu}$ $3.25 \%$, and $\mathrm{Al} 0.25 \%$. Fig. 2 displays the infrared absorption of calcined P. maxima shell samples. This figure demonstrates that $P$. maxima shells give a medium band absorption on 710.69 and $869.24 \mathrm{~cm}^{-1}$ frequency which is the typical absorption for $\mathrm{CaO}$ compounds bounding. Bond stretching vibration $\mathrm{Ca}-\mathrm{O}-$ $\mathrm{Ca}$ appears on band absorption around $874 \mathrm{~cm}^{-1}$ and Ca$O$ bond on around $712 \mathrm{~cm}^{-1}$ [24]. Band absorption with a very high intensity appears on $1795.39 \mathrm{~cm}^{-1}$ which is a stretching bond from double bond of $\mathrm{Ca}=\mathrm{O}$. The peak of the band widened to $1388.42 \mathrm{~cm}^{-1}$ with weak intensity due to asymmetric stretching vibration of $\mathrm{C}=\mathrm{O}$ from carbonate groups [8]. The structure or morphology of calcium oxide surface area from P. maxima shell can be seen in Fig. 3(a). This high calcium oxide content shows 


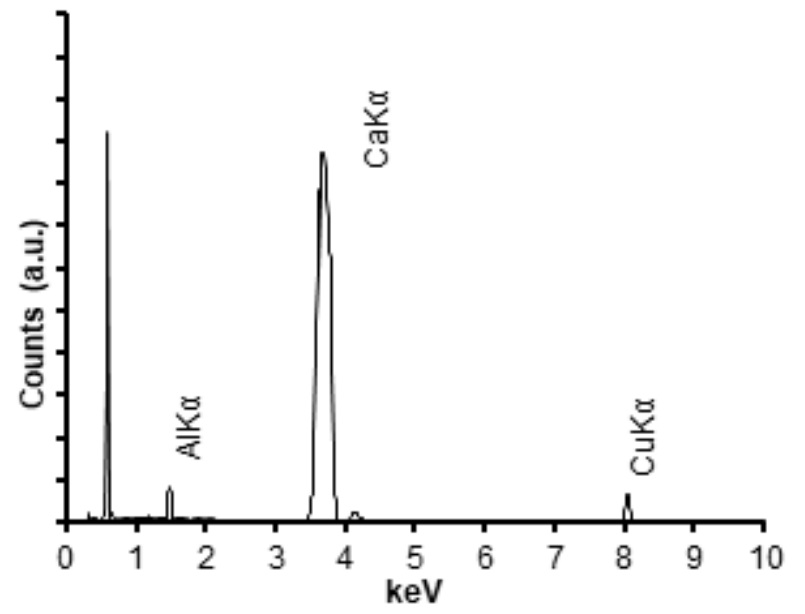

Fig 1. Energy Dispersive Spectroscopy (EDS) spectrum of calcium oxide by $P$. maxima shell

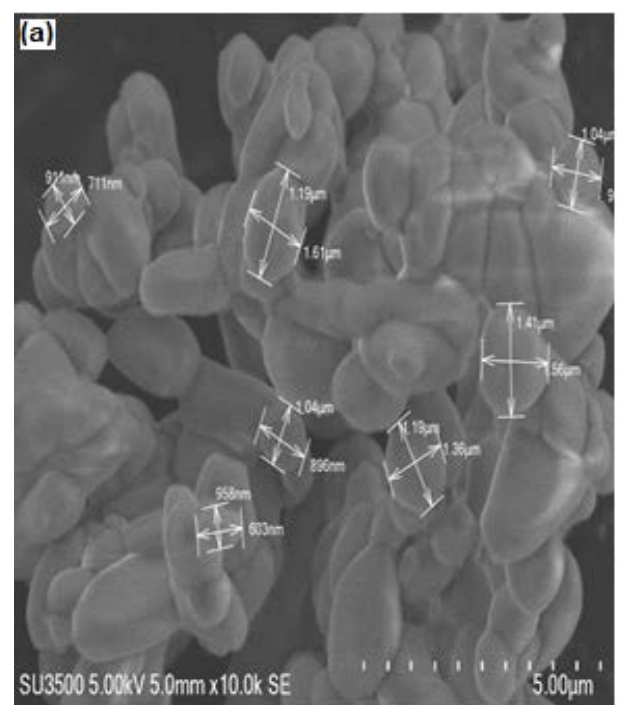

Fig 3. SEM image of $\mathrm{CaO}(\mathrm{a})$ and nano- $\mathrm{CaO}(\mathrm{b})$ as prepared by $P$. maxima shell maxima shell

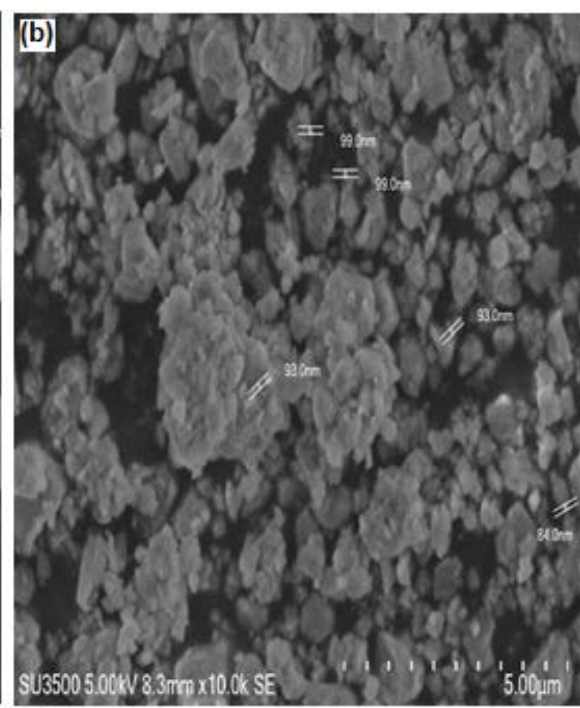

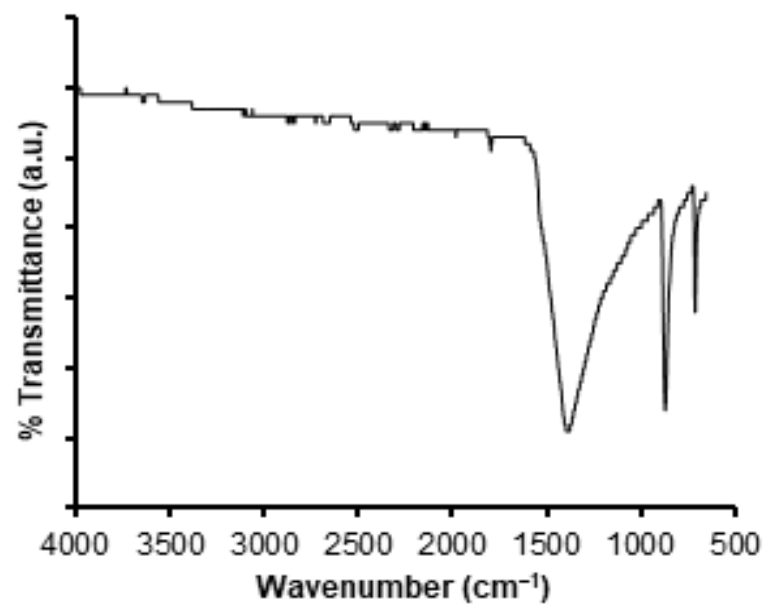

Fig 2. FT-IR spectra of calcium oxide as prepared by $P$.

Table 2. $\mathrm{L}_{9}\left(3^{4}\right)$ Orthogonal array design

that the P. maxima shells are potential as an alternative to heterogeneous base catalyst source that is green, environmentally friendly and inexpensive.

\section{CaO Nanoparticles Characterization Using Taguchi Method (Orthogonal Array, SNR, and ANOVA Analysis)}

The green catalyst coming from natural material in the development of its application has a trait which is not soluble in a mixture (heterogeneous), a low active site amount, large microporosity and molecule size thus these limit the mass transfer efficiency which cause the decrease

\begin{tabular}{ccccc}
\hline \multirow{2}{*}{ Experiment } & \multicolumn{4}{c}{ Factor } \\
\cline { 2 - 5 } & A & B & C & D \\
\hline 1 & 1 & 1 & 1 & 1 \\
2 & 1 & 2 & 2 & 2 \\
3 & 1 & 3 & 3 & 3 \\
4 & 2 & 1 & 2 & 3 \\
5 & 2 & 2 & 3 & 1 \\
6 & 2 & 3 & 1 & 2 \\
7 & 3 & 1 & 3 & 2 \\
8 & 3 & 2 & 1 & 3 \\
9 & 3 & 3 & 2 & 1 \\
\hline
\end{tabular}


of reaction rates, and the low conversion of the resulting product $[2,4]$. The efforts to improve the performances from this catalyst can be done by reducing its material size for up to nanometer. The catalyst in nanoparticle sizes has a large pore diameter, more specific surface area, and a lot of active sites. Nano-catalyst synthesis through green technology can be done through the top-down method by using ball mill technique [7,26].

Taguchi design has been chosen for nano-calcium oxide synthesis process of $P$. maxima shell because it can identify control factors which influence the particle size and generate products with high performance (robust) against outside interference (noise) optimally [25]. It is because Taguchi analysis uses equipment called orthogonal array (OA) and signal to noise ratio (SNR) which is supported by ANOVA [23,25]. Besides, this method is able to improve the product and process qualities and at the same time is able to reduce the cost and resources effectively [27]. The nano-calcium oxide product quality measured in this research is the particle size and specific surface area in which the quality characteristics used in sequence are smaller the better (STB) and larger the better (LTB).

The experiment is done based on the experiment matrix with $\mathrm{L}_{9}\left(3^{4}\right)$ orthogonal array on Table 2 which results in nine tests with replicated three times for each as the explanation in Table 3. The acquired data is processed by calculating the mean and SNR of each measurable quality parameter. The mean calculation is used to see the mean value from the response, while

Table 3. The optimized parameters for the four conditions (A-D) and their three levels in the design of experiment

\begin{tabular}{|c|c|c|c|c|}
\hline \multirow[b]{2}{*}{ Experiment } & \multicolumn{4}{|c|}{ Factor } \\
\hline & $\begin{array}{c}\text { A } \\
\text { (Milling time, } \mathrm{h} \text { ) }\end{array}$ & $\begin{array}{c}\text { B } \\
\text { (Ball-to-powder } \\
\text { weight ratio) }\end{array}$ & $\begin{array}{c}\mathrm{C} \\
\text { (Extent of filling } \\
\text { the vial, \%) }\end{array}$ & $\begin{array}{c}\mathrm{D} \\
\text { (Diameter of milling } \\
\text { beads, } \mathrm{mm} \text { ) }\end{array}$ \\
\hline 1 & 1 & $1: 10$ & 45 & 5 \\
\hline 2 & 1 & $2: 10$ & 50 & 10 \\
\hline 3 & 1 & $3: 10$ & 55 & 20 \\
\hline 4 & 2 & $1: 10$ & 50 & 20 \\
\hline 5 & 2 & $2: 10$ & 55 & 5 \\
\hline 6 & 2 & $3: 10$ & 45 & 10 \\
\hline 7 & 3 & $1: 10$ & 55 & 10 \\
\hline 8 & 3 & $2: 10$ & 45 & 20 \\
\hline 9 & 3 & $3: 10$ & 50 & 5 \\
\hline
\end{tabular}

Table 4. The mean values and SNR for particle size and specific surface area of the nano-calcium oxide P. maxima shell

\begin{tabular}{ccccccrrr}
\hline \multirow{2}{*}{ Experiment } & \multicolumn{3}{c}{ Factor } & \multicolumn{2}{c}{ Particle Size } & \multicolumn{2}{c}{ Specific Surface Area } \\
\cline { 2 - 9 } & A & B & C & D & Mean $(\mathrm{nm})$ & SNR $(\mathrm{dB})$ & \multicolumn{1}{c}{ Mean $\left(\mathrm{m}^{2} / \mathrm{g}\right)$} & \multicolumn{1}{c}{ SNR $(\mathrm{dB})$} \\
\hline 1 & 1 & 1 & 1 & 1 & $187.094 \pm 11.895$ & -45.453 & $6.547 \pm 0.771$ & 16.210 \\
2 & 1 & 2 & 2 & 2 & $199.557 \pm 3.530$ & -46.002 & $3.057 \pm 0.539$ & 9.404 \\
3 & 1 & 3 & 3 & 3 & $169.072 \pm 3.107$ & -44.562 & $4.665 \pm 0.485$ & 13.291 \\
4 & 2 & 1 & 2 & 3 & $142.051 \pm 6.300$ & -43.055 & $5.870 \pm 0.660$ & 15.265 \\
5 & 2 & 2 & 3 & 1 & $142.257 \pm 6.960$ & -43.068 & $6.065 \pm 1.047$ & 15.373 \\
6 & 2 & 3 & 1 & 2 & $173.374 \pm 10.300$ & -44.790 & $3.413 \pm 0.589$ & 10.432 \\
7 & 3 & 1 & 3 & 2 & $99.545 \pm 7.898$ & -39.979 & $11.421 \pm 0.868$ & 21.105 \\
8 & 3 & 2 & 1 & 3 & $132.369 \pm 10.248$ & -42.453 & $6.772 \pm 0.765$ & 16.503 \\
9 & 3 & 3 & 2 & 1 & $107.698 \pm 7.441$ & -40.658 & $8.255 \pm 0.468$ & 18.306 \\
\hline
\end{tabular}


SNR is to choose the largest factor level value in optimizing the experiment result in quality characteristics. The significant factors which influence the setting level and the contribution magnitude from each factor is measured by using an analysis of variance (ANOVA) of the 2013 Ms. Excel program.

Particle size is one of the important characteristics in catalyst characterization on nanoscale whose size is around $1 \mathrm{~nm}$ to $100 \mathrm{~nm}$ [28-29]. The smaller the particles size are, the larger its surface area so these particles have high catalytic activity in an efficient and quick product formation reaction [29-31]. The mean and SNR from the result of nano-calcium oxide synthesis research from $P$. maxima shell wastes can be seen in Table 4 . The data in this table shows that the mean of the smallest calcium oxide particle size obtained in experiment 7 is $99.545 \pm$ $7.898 \mathrm{~nm}$. Therefore, this sample belongs to a nanoscale particle or can be said as nano-calcium oxide. Surface structure analysis using SEM also points out that its particle length average is on the nanoscale range in accordance with Fig. 3(b). This data is also supported by analysis Fig. 4. Fig. 4 exhibits that nano-CaO compounds which appear on area $2 \theta$ around $32.192^{\circ}$ (JCPDS 77-2376) with high intensity have a size of $97.34 \mathrm{~nm}$ and tetragonal particle shape with 220 miller indexes. This particle shape is clearly shown by analysis result using TEM in accordance with Fig. 5. As a whole, Table 4 indicates that the milling time variable has a dominant effect, i.e. the longer the milling time of $P$. maxima shell, the smaller its particle size is. The increasing of time milling will reduce the particle size $[20,32]$.

The characteristic of nano-calcium oxide is not only determined by a single factor of milling time, but how much other control factors such as ball-to-powder weight ratio, the extent of filling the vial, and diameter of milling beads are contributed on synthesis process to get optimum characteristics. The determination of process condition with optimum nano-calcium oxide product characteristics is done through the analysis of mean, SNR, ANOVA and Taguchi multi-response loss function design approach which is transformed into SNR [23]. Therefore, the conclusion for the optimum factor level condition can be seen in Table 4 . Table 4 shows that factor A level 3 has the smallest value which means that this factor is the most influential factor to the mean for particle size response variable, so that factor A level 3 can be used to control the mean. Table 4 also shows that factor A level 3 is the factor whose SNR values is the biggest, it means that particle size response is also determined by factor A which is milling time. The best combinations for calculating mean and SNR is the same, in sequence based on the rank are A3, C3, B1, and D1. It indicates that these level and factor give a contribution to the particle size response mean and affect the noise.

Table 5 shows the ANOVA calculation result with a 95\% confidence level for the particles size response. It

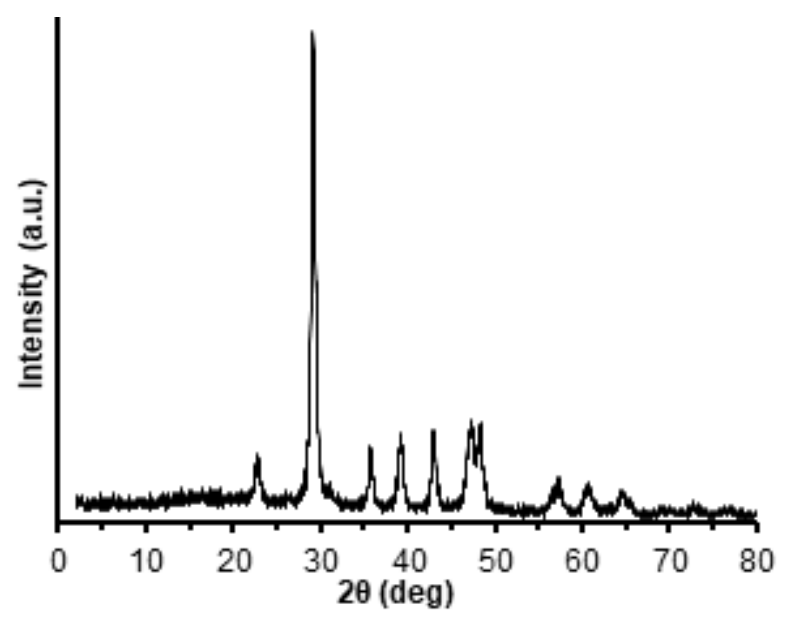

Fig 4. XRD image of nano- $\mathrm{CaO}$ as prepared by $P$. maxima shell

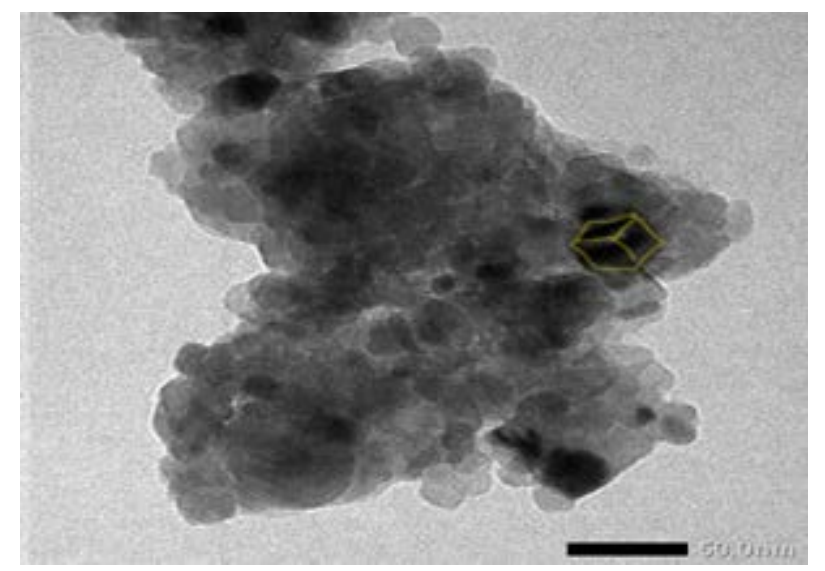

Fig 5. TEM image of nano- $\mathrm{CaO}$ as prepared by $P$. maxima shell 
Table 5. The ANOVA for the mean response of particle size

\begin{tabular}{lrrrrrr}
\hline \multicolumn{1}{c}{ Operational variable } & \multicolumn{1}{c}{ SS } & DoF & \multicolumn{1}{c}{ MS } & F-ratio & \multicolumn{1}{c}{ SS' $^{\prime}$} & P (\%) \\
\hline Milling time & 23418.78 & 2 & 11709.39 & 181.51 & 23289.76 & 78.44 \\
Ball-to-powder weight ratio & 1035.88 & 2 & 517.94 & 8.03 & 906.86 & 3.05 \\
Extent of filling the vial & 363.30 & 2 & 1681.65 & 26.07 & 3234.28 & 10.90 \\
Diameter of milling beads & 712.24 & 2 & 356.12 & 5.52 & 583.22 & 1.96 \\
Error & 1161.18 & 18 & 64.51 & 1.00 & 1677.26 & 5.65 \\
Total & 29691.38 & 26 & 1141.98 & & 29691.38 & 100.00 \\
\hline
\end{tabular}

Table 6. The ANOVA for the mean response of specific surface area

\begin{tabular}{lrrrrrr}
\hline \multicolumn{1}{c}{ Operational variable } & \multicolumn{1}{c}{ SS } & DoF & MS & F-ratio & \multicolumn{1}{c}{ SS' $^{\prime}$} & P (\%) \\
\hline Milling time & 90.91 & 2 & 45.45 & 89.75 & 89.89 & 54.39 \\
Ball-to-powder weight ratio & 39.88 & 2 & 19.94 & 39.37 & 38.86 & 23.51 \\
Extent of filling the vial & 18.09 & 2 & 9.04 & 17.86 & 17.08 & 10.33 \\
Diameter of milling beads & 7.29 & 2 & 3.64 & 7.20 & 6.28 & 3.80 \\
Error & 9.12 & 18 & 0.51 & 1.00 & 13.17 & 7.97 \\
Total & 165.28 & 26 & 6.36 & & 165.28 & 100.00 \\
\hline
\end{tabular}

has been known that there are three control factors which affect the experiment result, i.e. factor $\mathrm{A}, \mathrm{C}$, and $\mathrm{B}$ with $\mathrm{F}$ ratio value is bigger than $\mathrm{F}$ table by factor contribution value in sequences are $78.44,10.90$, and $3.05 \%$. Factor D (diameter of the milling beads) does not affect the experiment result with an $\mathrm{F}$ ratio value is smaller than $\mathrm{F}$ table value and its factor contribution value is $1.96 \%$.

The specific surface area is one of the most crucial parameters in determining heterogeneous catalyst quality because the bigger the catalyst surface area is, the more its particle pore sites are, so the collision process or mobilization between reactant particles in a reaction can happen more actively and quickly [29-30]. In this study, the engineering of the surface area of calcium oxide particles from the P. maxima shells was carried out through the green nanotechnology approach [21] by using PPF-UG Shaker mill equipment, Taguchi experimental design and Brunauer-Emmett-Teller (BET) method. Mean and SNR surface area from each experiment are shown in Table 4. This table denotes that mean and the biggest SNR surface area of nano-calcium oxide are yielded on experiment 7 , sequentially the value is $11.421 \pm 0.868 \mathrm{~m}^{2} / \mathrm{g}$ and $21.105 \mathrm{~dB}$. This condition is achieved on the milling process for $3 \mathrm{~h}$, ball-to-powder weight ratio $1: 10$, the extent of filling the vial $55 \%$ and diameter of milling beads $10 \mathrm{~mm}$. Meanwhile, the smallest particle mean and SNR surface area is achieved in experiment 2, i.e. $3.057 \pm 0.539 \mathrm{~m}^{2} / \mathrm{g}$ and $9.404 \mathrm{~dB}$. Table 4 shows that factor A level 3 is the most influential factor to mean for the specific surface area response variable in the making process of nano-calcium oxide from $P$. maxima shell, so factor A level 3 can be used to control the mean. The biggest SNR value is also on factor A level 3. Table 4 indicates that the best combination of mean and SNR calculation is alike, i.e. A3, B1, C3, and D1. It shows that these level and factors give influence to the specific surface area response mean and these influence the noise. Based on the ANOVA calculation result in Table 6 for specific surface area response it is discovered that all factors affect the experiment result with an $\mathrm{F}$ ratio value is larger than the $\mathrm{F}$ table. The contribution of each factor to specific surface area response in the sequence are factor A $54.39 \%$, factor B $23.51 \%$, factor C $10.33 \%$ and factor D $3.80 \%$. The length of the sample milling process time is the most influential factor for the specific surface area [29].

Catalyst surface engineering from P. maxima shell using ball mill process with shaker mill instruments has been able to increase the magnitude of the specific surface area. Panjaitan et al. report that wet-nano grinding process with planetary ball mill instruments has been able to increase the nanocatalyst surface area by 
the increasing of grinding time [29]. From the analysis result using the Brunauer-Emmett-Teller (BET) approach, it is obtained that $P$. maxima shell powder which passes the 200 mesh sieve has the average specific surface area of $1.888 \pm 0.802 \mathrm{~m}^{2} / \mathrm{g}$. This sample treatment using shaker mill is in accordance with the data shown in Table 4 was able to increase the specific surface area for up to $229.93 \%$. The success of specific surface area engineering from $P$. maxima shell through ball mill method is expected to boost the work capability, performance and economic value from P. maxima shell as a heterogeneous catalyst.

\section{Multi-response Signal to Noise Analysis}

Multi-response analysis with Taguchi loss function approach is chosen for this research because there is two quality parameter that is used, i.e. particle size and specific surface area. Characteristic value from these two parameters uses a different value, namely STB for particle size and LTB for the specific surface area. Therefore, before calculating the total loss function, data normalization is done for each characteristic. The calculation result of multi-response loss function which is transformed into the calculation of SNR factor effect can be seen in Table 7 . This table displays the combination level and factor on optimum condition which affects the calcium oxide quality from $P$. maxima shell respectively are factor A3, B1, D1, and C3. This optimum factor level condition (A3B1C3D1) is in line with the data of multiresponse calculation result with the Taguchi Loss Function approach which is proposed in Table 7. This table shows that the highest SNR multi-response value is acquired in experiment condition number 7 is equal to $5.147 \mathrm{~dB}$. The most important factor to particles size and the specific surface area is the milling time; the longer the milling process is, the smaller the particles size is [20] and the bigger its specific surface area is [29]. The second factor is ball-to-powder weight ratio, the research outcome demonstrates that a 1:10 ratio can produce nano-calcium oxide with the particles size mean is $99.545 \mathrm{~nm}$. The third factor is the diameter of milling beads of $5 \mathrm{~mm}$ can produce a better product compared to other sizes. Tao et al. have produced a nano-copper that is $33 \mathrm{~nm}$ in ball-to-powder weight ratio 1:10 and the diameter of milling beads of $6.4 \mathrm{~nm}$ [32]. The extent of filling the vial condition is the fourth factor which affects the nano-calcium oxide production production process. This factor is intended to keep the available space on the grinder container after the filling of milling balls and

Table 7. The result of calculating MRSN (multi-response signal to noise) procedure of nano-CaO P. maxima shell

\begin{tabular}{ccccccc}
\hline \multirow{2}{*}{ Experiment } & \multicolumn{2}{c}{ Particle size } & \multicolumn{2}{c}{ Specific surface area } & \multirow{2}{*}{ TLj } & \multirow{2}{*}{ MRSN $\left(\eta_{j}\right)$} \\
\cline { 2 - 5 } & Loss & Nij & Loss & Nij & & \\
\hline 1 & 0.754 & 1.508 & 0.284 & 0.567 & 1.038 & -0.161 \\
2 & 0.856 & 1.712 & 1.359 & 2.719 & 2.215 & -3.454 \\
3 & 0.614 & 1.229 & 0.556 & 1.111 & 1.170 & -0.682 \\
4 & 0.434 & 0.868 & 0.353 & 0.705 & 0.787 & 1.042 \\
5 & 0.436 & 0.871 & 0.344 & 0.688 & 0.779 & 1.082 \\
6 & 0.647 & 1.295 & 1.073 & 2.146 & 1.720 & -2.356 \\
7 & 0.214 & 0.428 & 0.092 & 0.184 & 0.306 & 5.147 \\
8 & 0.378 & 0.756 & 0.265 & 0.530 & 0.643 & 1.917 \\
9 & 0.166 & 0.333 & 0.175 & 0.350 & 0.341 & 4.666 \\
\hline
\end{tabular}

Table 8. The result of calculating a confidence interval

\begin{tabular}{cllr}
\hline Num. & \multicolumn{1}{c}{ Parameter } & \multicolumn{1}{c}{ Confidence Interval } & \multicolumn{1}{c}{ Result } \\
\hline 1 & Particle size $(\mathrm{nm})$ & Optimal condition & $99.822 \pm 10.262$ \\
& & Confirmation experiments & $93.407 \pm 14.800$ \\
2 & \multirow{2}{*}{ Specific surface area $\left(\mathrm{m}^{2} / \mathrm{g}\right)$} & Optimal condition & $10.533 \pm 1.117$ \\
& & Confirmation experiments & $9.260 \pm 1.612$ \\
\hline
\end{tabular}


sample powder is not spacious nor crowded. According to Hadef, the filling that is too little will cause a low productivity level, likewise overfill will cause the movement of the milling beads has not enough space so that the resulting product performance is less optimum [19]. The filling up to $55 \%$ can produce a product performance is optimum.

\section{Confirmation Experiment}

This experiment is done based on the factor and level of an optimal condition which is acquired from the calculation of loss function multi-response as much as 5 samples. The result of the confirmation experimental are valid if the results are within the optimal confidence interval. Table 8 shows the calculation result of confirmation confidence interval which is compared to optimal condition confidence interval is at $95 \%$ confidence level. Based on the interpretation of confidence interval calculation result on nano-CaO quality parameter shown in Table 8 , it can be known that the mean of confirmation experiment is within optimum condition interval. It shows that the optimum factor level combination produced in this research can increase nano- $\mathrm{CaO}$ quality.

\section{- CONCLUSION}

The quality parameter of nano-calcium oxide product from $P$. maxima are affected by 4 major factors, i.e. milling time, the extent of filling the vial, diameter of milling beads and ball-to-powder weight ratio. The Taguchi multi-response loss function analysis results an optimum factor and level combination under A3B1D1C3 process condition with particle size means of $93.407 \mathrm{~nm}$ and surface area of $9.260 \mathrm{~m}^{2} / \mathrm{g}$. This corresponds to a milling time of $3 \mathrm{~h}$, a ball-to-powder weight ratio of 1:10, a diameter of milling beads of $5 \mathrm{~mm}$, and an extent of filling the vial of $55 \%$.

\section{- ACKNOWLEDGMENTS}

We would like to acknowledge valuable inputs from our colleagues at Universitas Gadjah Mada and Ministry of Agriculture. Special thank was also acknowledged for the financial support from SEAMEO SEARCA (Contract No. 1038459-11/15/16/NOT.COM. No. 26-2017-C) for our graduate study.

\section{- REFERENCES}

[1] Helwani, Z., Othman, M.R., Aziz, N., Kim, J., and Fernando, W.J.N, 2009, Solid heterogeneous catalysts for transesterification of triglycerides with methanol: A review, Appl. Catal., A, 363 (1-2), 110.

[2] Sani, Y.M., Wan Daud, W.M.A., and Aziz, A.R.A., 2013, Solid acid-catalyzed biodiesel production from microalgal oil-The dual advantage, $J$. Environ. Chem. Eng., 1 (3), 113-121.

[3] Abdullah, S.H.Y.S., Hanapi, N.H.M., Azid, A., Umar, R., Juahir, H., Khatoon, H., and Endut, A., 2017, A review of biomass-derived heterogeneous catalyst for a sustainable biodiesel production, Renewable Sustainable Energy Rev., 70, 1040-1051.

[4] Zabeti, M., Wan Daud, W.M.A., and Aroua, M.K., 2009, Activity of solid catalysts for biodiesel production: A review, Fuel Process. Technol., 90 (6), 770-777.

[5] Konwar, L.J., Boro, J., and Deka, D., 2014, Review on latest developments in biodiesel production using carbon-based catalysts, Renewable Sustainable Energy Rev., 29, 546-564.

[6] Zein, Y.M., Anal, A.K., Prasetyoko, D., and Qoniah, I., 2016, Biodiesel production from waste palm oil catalyzed by hierarchical ZSM- 5 supported calcium oxide, Indones. J. Chem., 16 (1), 98-104.

[7] Yutthalekha, T., Wattanakit, C., Warakulwit, C., Wannapakdee, W., Rodponthukwaji, K., Witoon, T., and Limtrakul, J., 2017, Hierarchical FAU-type zeolite nanosheets as green and sustainable catalysts for benzylation of toluene, J. Cleaner Prod., 142 (Part 3), 1244-1251.

[8] Pandit, P.R., and Fulekar, M. H., 2017, Egg shell waste as heterogeneous nanocatalyst for biodiesel production: Optimized by response surface methodology, J. Environ. Manage., 198 (Part 1), 319-329.

[9] Gardy, J., Hassanpour, A., Lai, X., Ahmed, M.H., and Rehan, M., 2017, Biodiesel production from used cooking oil using a novel surface functionalised $\mathrm{TiO}_{2}$ nano-catalyst, Appl. Catal., B, 207, 297-310. 
[10] Nurfitri, I., Maniam, G.P., Hindryawati, N., Yusoff, M.M., and Ganesan, S., 2013, Potential of feedstock and catalysts from the waste in biodiesel preparation: A review, Energy Convers. Manage., 74, 395-402.

[11] Taufiq-Yap, Y.H., Lee, H.V., and Lau, P.L., 2012, Transesterification of Jatropha curcas oil to biodiesel by using short-necked clam (Orbicularia orbiculata) shell, Energy Explor. Exploit., 30 (5), 853-866.

[12] Lesbani, A., Tamba, P., Mohadi, R., and Fahmariyanti, 2013, Preparation of calcium oxide from Achatina fulica as catalyst for production of biodiesel from waste cooking oil, Indones. J. Chem., 13 (2), 176-180.

[13] Nurhayati, Anita, S., Amri, T.A., and Linggawati, A., 2017, Esterification of crude palm oil using $\mathrm{H}_{2} \mathrm{SO}_{4}$ and transesterification using $\mathrm{CaO}$ catalyst derived from Anadara granosa, Indones. J. Chem., 17 (2), 309-315.

[14] Pratikha, R.S., Syukri, and Admi, 2013, Synthesis and characterization of acetonitrile ligated $\mathrm{Cu}$ (II)complex and its catalytic application for transesterification of frying oil in heterogeneous phase, Indones. J. Chem., 13 (1), 72-76.

[15] Banković-Ilić, I.B., Miladinović, M.R., Stamenković, O.S., and Veljković, V.B., 2017, Application of nano $\mathrm{CaO}$-based catalysts in biodiesel synthesis, Renewable Sustainable Energy Rev., 72, 746-760.

[16] Hussain, S.T., Ali, S.A., Bano, A., and Mahmood, T., 2011, Use of nanotechnology for the production of biofuels from butchery waste, Int. J. Phys. Sci., 6 (31), 7271-7279.

[17] Ortiz, A.L., Sánchez-Bajo, F., Candelario, V.M., and Guiberteau, F., 2017, Comminution of $\mathrm{B}_{4} \mathrm{C}$ powders with a high-energy mill operated in air in dry or wet conditions and its effect on their spark-plasma sinterability, J. Eur. Ceram. Soc., 37 (13), 3873-3884.

[18] Enayati, M.H., Aryanpour, G.R., and Ebnonnasir, A., 2009, Production of nanostructured WC-Co powder by ball milling, Int. J. Refract. Met. Hard Mater., 27 (1), 159-163.

[19] Hadef, F., 2017, Synthesis and disordering of $\mathrm{B}_{2}$ TM$\mathrm{Al}(\mathrm{TM}=\mathrm{Fe}, \mathrm{Ni}, \mathrm{Co})$ intermetallic alloys by high energy ball milling: A review, Powder Technol., 311, 556-578.

[20] Madan, S.S., and Wasewar, K.L., 2017, Optimization for benzeneacetic acid removal from aqueous solution using $\mathrm{CaO}$ nanoparticles based on Taguchi method, J. Appl. Res. Technol., 15 (4), 332-339.

[21] Mosaddegh, E., Hassankhani, A., Pourahmadi, S., and Ghazanfari, D., 2013, Ball mill-assisted preparation of nano- $\mathrm{CaCO}_{3}$ as a novel and green catalyst-based eggshell waste: A green approach in the synthesis of pyrano[4,3-b ]pyrans, Int. J. Green Nanotechnol., 1, 1-5.

[22] Ross, P.J., 1996, Taguchi Techniques for Quality Engineering: Loss Function, Orthogonal Experiments, Parameter and Tolerance Design, McGraw Hill Professional, New York.

[23] Musabbikhah, Saptoadi, H., Subarmono, and Wibisono, M.A., 2017, Modelling and optimization of the best parameters of rice husk drying and carbonization by using Taguchi method with multi response signal to noise procedure, Int. J. Renewable Energy Res., 7 (3), 1219-1227..

[24] Anantharaman, A., Ramalakshmi, S., and George, M., 2016, Green synthesis of calcium oxide nanoparticles and its applications, Int. J. Eng. Res. Appl., 6 (10), 27-31.

[25] Kim, S.M., Park, K.S., Kim, K.D., Park, S.D., and Kim, H.T., 2009, Optimization of parameters for the synthesis of bimodal Ag nanoparticles by Taguchi method, J. Ind. Eng. Chem., 15 (6), 894-897.

[26] Badrul, H.M., Rahmat, N., Steven, S., Syarifah, F., Shelly, W., and Agung, P.F., 2014, Synthesis and Characterization of Nano Calcium Oxide from Eggshell to be Catalyst of Biodiesel Waste Oil, Proceedings of the $3^{\text {rd }}$ Applied Science for Technology Innovation, ASTECHNOVA 2014, Yogyakarta, 1314 August, 2014, 340-345.

[27] Poorebrahimi, S., and Norouzbeigi, R., 2015, A facile solution-immersion process for the fabrication of superhydrophobic gibbsite films with a binary micro-nano structure: Effective factors optimization via Taguchi method, Appl. Surf. Sci., 356, 157-166. 
[28] Katata-Seru, L., Lebepe, T.C., Aremu, O.S., and Bahadur, I., 2017, Application of Taguchi method to optimize garlic essential oil nanoemulsions, J. Mol. Liq., 244, 279-284.

[29] Panjaitan, F.R., Yamanaka, S., and Kuga, Y., 2017, Soybean oil methanolysis over scallop shell-derived $\mathrm{CaO}$ prepared via methanol-assisted dry nanogrinding, Adv. Powder Technol., 28 (7), 1627-1635.

[30] Elcioglu, E.B., Yazicioglu, A.G., Turgut, A., and Anagun, A.S., 2018, Experimental study and Taguchi analysis on alumina-water nanofluid viscosity, Appl. Therm. Eng., 128, 973-981.

[31] Acisli, O., Khataee, A., Karaca, S., Karimi, A., and Dogan, E., 2017, Combination of ultrasonic and Fenton processes in the presence of magnetite nanostructures prepared by high energy planetary ball mill, Ultrason. Sonochem., 34, 754-762.

[32] Tao, J.M., Zhu, X.K., Scattergood, R.O., and Koch, C.C., 2013, The thermal stability of high-energy ball-milled nanostructured Cu, Mater. Des., 50, 22-26. 